\title{
A Prototypical Model on Hakka Serial Verb Constructions
}

\author{
Yu-Ching Tseng ${ }^{1}$ \\ ${ }^{1}$ Department of English, Tamkang University, Taiwan \\ Correspondence: Yu-Ching Tseng, Department of English, No.151, Yingzhuan Rd., Tamsui Dist., New Taipei \\ City 25137, Taiwan. E-mail: ychtseng@mail.tku.edu.tw
}

Received: November 13, $2020 \quad$ Accepted: December 16, $2020 \quad$ Online Published: December 22, 2020

doi:10.5539/ijel.v11n2p1 URL: https://doi.org/10.5539/ijel.v11n2p1

\begin{abstract}
This research paper provides a meaning-based account to examining Hakka syntactic constructions that comprise multiple verbs in their scope. The investigation is based on an interdisciplinary approach from the interface of syntax and semantics. The paper is organized into two main parts. The first part of this paper claims that the prototypical construction of the serial verb construction is a syntactic configuration that contains two verbs in the same clause, indicating two interdependent subevents happening at close time intervals. In addition, the paper proposes that greater distance in structural and semantic interdependence between the two verbs forms a gradation deviating from the prototype. In this part, a prototype model, rather than a criterial attribute model, is adopted to define the Hakka serial verb construction (SVC). The second part of paper provides a typological study that classifies the Hakka SVCs into subtypes based on the syntactic structure and the semantic relationship of the component verbs. Syntactic tests are used to test the clausehood of the multi-verb constructions identified in this part.
\end{abstract}

\section{Keywords: serial verb construction, Hakka, prototype, syntax, semantics interface}

\section{Hakka Serial Verb Construction}

In this section, we first briefly review the wild discussions surrounding the SVC in the literature of linguistics in terms of the basic definition and scope of the syntactic configuration. Then we show that the prototype theory better captures the uncertainty of the construction in comparison with the tradition criterial-attribute model.

\subsection{Literature on $S V C$}

Serial verb construction (SVC) has undergone quite intensive and extensive discussions by many linguists around the world. An issue that has not yet achieved consensus concerns what should and should not be considered an SVC. The construction can be defined broadly as including any string of verb phrases or clauses juxtaposed together. As in Li and Thompson's (1981) definition of Chinese SVCs, all the following constructions are recognized as SVCs as long as there is no grammatical marker occurring between the two constituents (Li \& Thompson, 1981, p. 594): (1) Two or more separate events. (2) One verb phrase serving as the subject or direct object of another verb. (3) Pivotal constructions. (4) Descriptive clauses. Under this definition, an SVC comprises both single and multiple clauses. On the other hand, more linguistic studies have proposed a mono-clausal schema to describe the structure of SVCs. For example, Steward (1963) and Bamgbose (1974) suggested that an SVC is a mono-clause formed from two or more underlying clauses, which may involve meaning change during the process of syntactic transformation. Dai (1990) distinguished three types of SVC: subordination, coordination, and serialization. However, he argued that only serialization forms a true SVC, while subordination and coordination are noted as single-headed and double-headed multiclausal constructions, respectively.

A number of studies have contributed to a categorization of SVC subtypes. Some research involved cross-linguistic investigations, such as Aikhenvald (2006a), who argued that four parameters can be adopted to categorize SVCs. Composition distinguishes between the symmetrical type, in which two component verbs have equal status, and the asymmetrical type, in which the two verbs show a target-modifying relationship. Contiguity distinguishes between the contiguous type, which contains two verbs in a row, and the noncontiguous type, which allows other constituents intervening between the verbs. Wordhood distinguished between one-word and multiword constructions. Inflection distinguishes between single marking and concordant marking. In contrast, the classification of SVCs in other studies was based on investigations of one particular language. Christaller 
(1875) studied Tshi and divided the construction into two basic types: essential and accidental. The former type involves two verbs that show inseparable relationships, and the latter type involves two verbs that happen to be joined together. This distinction is commonly recognized as subordination and coordination by other linguists, including Chao (1968), Chen (1993), and Dai (1990), who characterized the construction by investigating Mandarin Chinese.

The SVC in Mandarin Chinese has been investigated thoroughly in many studies from the perspectives of syntax and semantics or the interface of the two areas. According to Fan (2016), SVCs can be divided into nuclear and core SVCs. A nuclear SVC contains one predicate whose syntactic argument is selected from the argument structure at the semantic level. A core SVC contains two cores that possess two separate argument structures, and only the subject argument of the first core can be realized in the syntactic structure through subject-argument fusion. Core SVCs can further be classified into subtypes such as the instrumental type, excessive type, and purposive type based on the semantic relationship of the two components. Yin (2012) analyzed five main types of SVC: coordinate constructions, complement constructions, purposive constructions, shared object constructions, and VV compounds; Yin argued that the component verbs in these SVCs exhibit some semantic interdependence that is argued to be based on a set of iconic principles. Yip and Rimmington (2016) called the serial construction a chain construction, which strings two or more verbal predicates to form a sentence. The multiple verb constructions, according to their classification, include at least the locative, purposive, causative, circumstantial, consecutive, simultaneous, and idiomatic subtypes. This classification is based on the meaning relationship between the verbs.

As is apparent, the literature contains no agreed-upon formal criteria for the identification of true SVCs as a distinctive construction, apart from other kinds of multiverb constructions, or for a precise subclassification within the general SVC category. This paper identifies the SVC into two kinds. The general SVC is defined as generally as possible, including syntactic configurations that contain at least two verbs in their structural scopes as long as they share the same grammatical subject. The SVC prototype suggests a stricter sense of the construction, adhering to the pursuit of a syntactic configuration that fits the more focal, fundamental definition. A more thorough discussion is given in the following section.

\subsection{The Prototype of SVC}

The formal generative approaches usually adopt the criterial-attribute model to define linguistic structure and deal with linguistic categorization, in which a category is defined by a set of features and membership to a class requires the possession of all the properties on the list. However, as discussed in Section 1.1, since there is no agreement among linguists concerning what kind of syntactic configuration should be considered an SVC, one can hardly come up with a complete list of criterial attributes for the SVC that identifies all the members and filters out all the nonmembers. Instead, this paper follows the cognitive tradition and adopts the prototype theory. The theory originated in cognitive psychology in the 1970s (Rosch, 1973, 1975, 1977; Rosch \& Mervis, 1975) and was adopted by linguists around the early 1980s. Since then, the prototype theory has grown steadily and was established as a central notion, especially in the field of cognitive semantics (Wierzbicka, 1985; Lakoff, 1987; Langacker, 1987). In this paper we are concerned with the theoretical application in the subfield of linguistics. The prototype model proposes a graded categorization in which categorization is regarded as a matter of degree. In the prototype model, some members of a category are considered more central, recognized as the prototypical instances, whereas other members form a gradation from central to peripheral depending on the distance by which they deviate from the prototype.

The SVC label should ideally be general to include all structural patterns that contain more than one verb that share the same grammatical subject in the syntactic scope, wherein each verb indicates a subevent that cooperates with other subevents to form a main event. Figure 1 diagrams the situation. The component subevents are shown as boxes. These boxes are interconnected with semantic relations, which are indicated by association lines. These subevents are enclosed by a solid, thick-line circle to indicate that they collectively form a larger main event. 


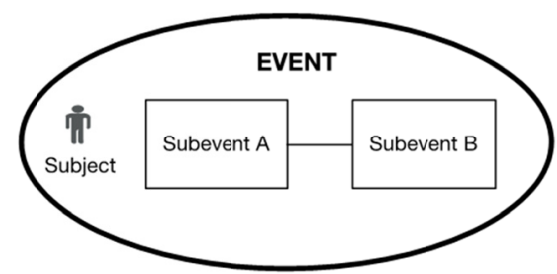

Figure 1.Semantic diagram of SVCs

The configuration in Figure 1 is general enough to predict a variety of syntactic structures, and they are organized around the core of the most prototypical of the SVC constructions. Under this general definition, we claim that a syntactic construction is identified as an SVC as long as it possesses the features listed in (1).

(1) Features of General SVCs

a. Two verbs are present.

b. The two verbs collectively contribute to a single event that contains only one overt subject.

c. The two verbs are semantically related to one another.

d. The two verbs may occur in the same clause or in different clauses.

It is hard to propose a unified account of SVC that can account for a large variety of languages. However, linguists try to broadly define the construction based on some characteristics that seem to be cross-linguistically applicable (Aikhenvald, 2006b; Baker, 1989; Bisang, 1995; Haspelmath 2016). The proposals can be summarized as follows. An SVC is a mono-clausal construction containing multiple independent verbs. The component verbs cannot switch their position, they cannot be intervened by other words, nor can a grammatical marker appear to indicate their relationship. The juxtaposed verbs do not show predicate-argument relation with one another. They share the same subject and collaborate to form a single event consisting of a series of related actions. Based on this summarized definition, we claim that syntactic configurations that qualify as an SVC prototype should possess the fundamental features listed in (2).

(2) Features of Prototypical SVCS

a. Two verbs are present in the same clause, and the order of the two verbs is fixed.

b. The two verbs should be close to one another.

c. No grammatical linker is present to indicate the relationship of the verbs.

d. The two verbs collectively contribute to a single event that contains only one overt subject.

e. The two verbs are semantically related to one another, but they do not show predicate-argument relation with one another.

Adhering to the definitions of the two kinds of SVC, we propose that the co-occurring verbs found in (3a) and (3b) form an SVC prototype. In (3a), the two verbs suy ("deliver") and van ("return") cooperate to express an action indicating the purpose of the idiot's behavior. In (3b), the verbs luy ("tease") and p'ian ("cheat") collectively constitute the evil monk's action toward the villagers. In both cases the two verbs are juxtaposed without grammatical linker indicating their relationship. They share the same subject, and they do not show predicate-argument relationship (Note 1).

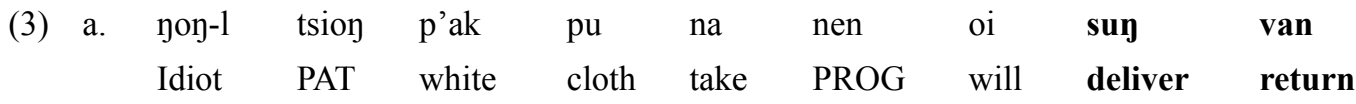
nin.

person

"The idiot is holding the white cloth in his hands and planning to send it back to the person." (pp. 108-109)

b. Teupai zu zit kai za vofon, t5'ont'eu tso fai

Before have one CL evil monk often do evil 


$\begin{array}{llll}\text { sï, } & \text { luy } & \text { p'ian } & \text { hionmin. } \\ \text { deed } & \text { tease } & \text { cheat } & \text { villager }\end{array}$

"A long time ago, there was an evil monk, who often conducted evil deeds, cheating the villagers." (p. 101)

By contrast, those co-occurring verbs found in (4) do not form prototypical SVCs. They are identified as atypical SVC as they possess all of the features listed in (1) but violate some of the features listed in (2). In (4a) the two verbs name two daily chores that Hakka people usually do in the countryside. In (4b) the two verbs are semantically related in that the first verb indicates the manner that describes how the subject talks to someone. In (4c), a cause-effect relationship is identified. In (4d), a propositional saying verb brings another clause as the complement. However, as shown here, at least one of the features listed in (2) is violated. For (4a), the two verbs can switch their position without changing the meaning of the sentence, violating (2a). As to (4b), there are elements intervening between the two verbs, violating ( $2 b)$. In (4c), a grammatical linker zen ("because") is overt indicating the cause-effect relationship of the two verbal components, violating (2c). In (4d), the two verbs are bound in a predicate-argument relation, violating (2e).

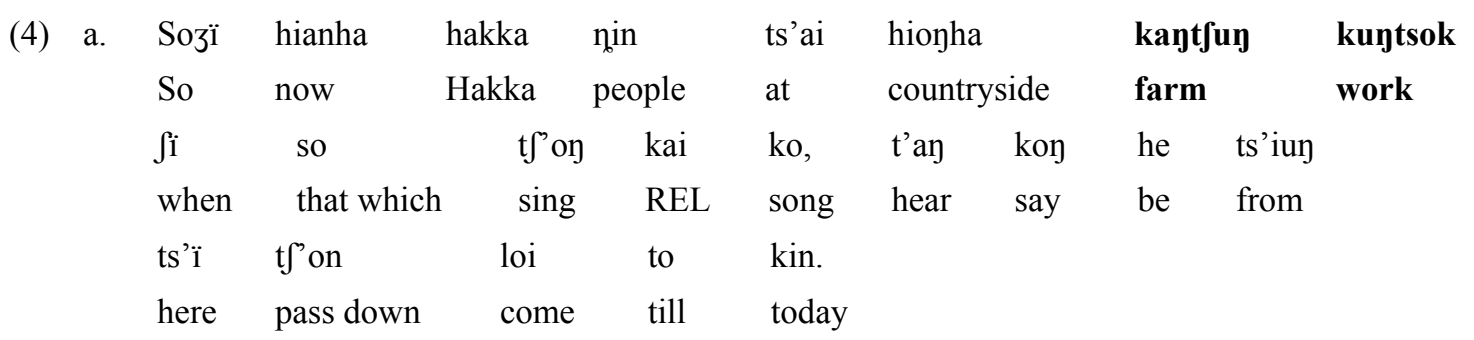

"So, I heard that the songs that the Hakka people living in the countryside nowadays sing while farming and working has been passed down to modern times from before." (p. 120)

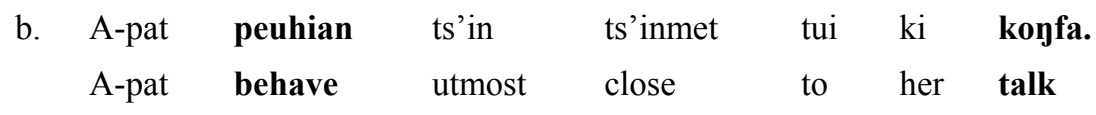

"A-pat tried to be close to her while talking to her." (p. 135)

c. zen mo kok m $m$ tet foy...

Because have no horn NEG can go up

Since [the dragon] doesn't have a horn, [he] cannot go up [to the sky] ...” (p. 115)

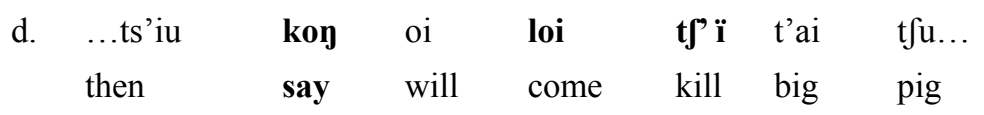

“...then [he] said he will come to kill a big pig...” (p. 181)

As to (5), the sentences include non-SVC examples. They violate at least one feature in both (1) and (2). In (5a), the two verbs indicate two events. The time expressions ts'okpunit ("yesterday") and kimpunit ("today") signal that the two events are proceeding along different timelines. The continuity of a time span is interrupted by the introduction of a time signal. In (5b), the two verbs ts 'iufui ("swim") and pa ("carry on the back") have different subjects. Any switch of the subject introduces a new event because subject change signals some kind of discourse discontinuity. Therefore, (5a) and (5b) are not serial verb constructions due to violation of both (1) and (2).

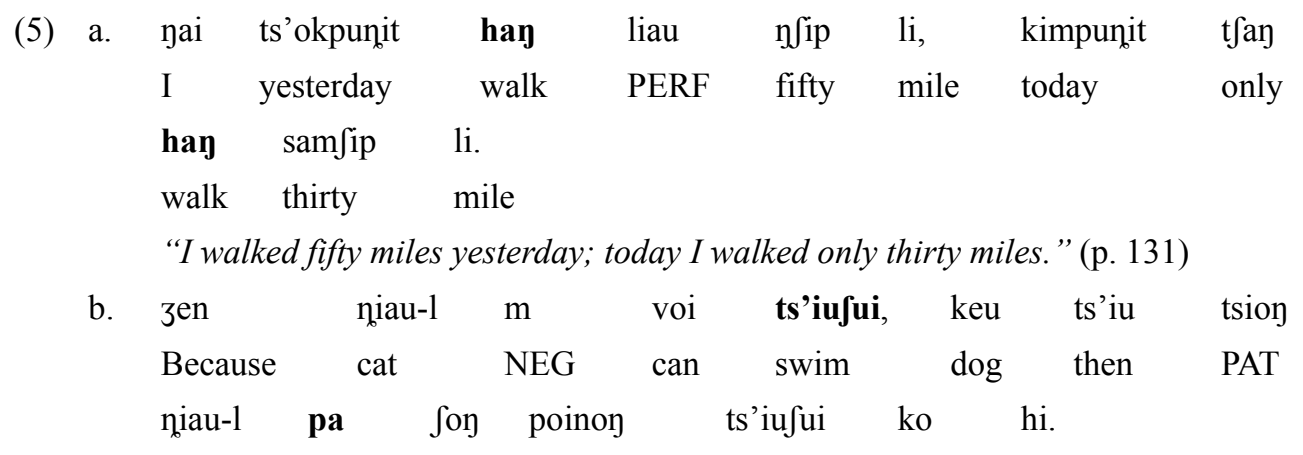


cat carry on shoulder swim past go

"Because the cat cannot swim, the dog then carried it on the shoulder and swam past [the river].” (p. 117)

A tentative prototype model for SVCs is shown in Figure 2.



Figure 2. Prototype model for general SVCs

The inner circle includes all the prototypical SVCs that fulfill the features listed in (1) and (2). One layer outside the core circle are non-typical SVCs. This circle includes multi-verb constructions that fulfill (1) but violate some of the features in (2). Outside the circle is non-SVC structures, including those that violate (1) and (2). These constructions deviate most significantly from the prototypical SVCs. As shown in this section, as a construction approaches the inner circle, it is classified into a more typical or canonical category of SVC.

\section{Subtypes of SVCs}

In this section, we first divide non-SVCs from SVCs, and then argue that Hakka serial verb constructions, including prototypical and non-prototypical SVCs, can be further classified into different categories based on the syntactic structure of the construction and the semantic relationship of their component verbs. In this paper, we also try to refine the prototype model shown in Figure 2 by adding more circles to subdivide the non-typical SVCs into layers based on the distance by which different syntactic configurations deviate from the prototype. Some syntactic tests are applied in this section to test the clausehood of a multiverb construction.

\subsection{Non-SVCs}

Not all multi-verb constructions are identified as serial verb constructions. As mentioned in Section 1.2, constructions that violate some critical features in (1) are not considered SVCs. To be specific, constructions that do not contain at least two verbs are not SVCs. However, even if a syntactic construction contains two verbs, it is not an SVC if both of the verbs co-occur with an overt subject, or the semantic relation between the two subevents is not strongly bound with one another. Examples have been shown earlier in (5), which we repeat in the following (6), along with some other similar examples.

\begin{tabular}{lllllllllll} 
(6) & zen & \multicolumn{2}{c}{ niau-l } & $\mathrm{m}$ & voi & ts'iufui, & keu & ts'iu & tsion \\
Because & cat & NEG & can & swim & dog & then & PAT \\
niau-1 & pa & fon & poinon & ts'iufui & ko & hi. & & & \\
cat & carry & on & shoulder & swim & past & go & &
\end{tabular}

"Because the cat cannot swim, the dog then carried it on the shoulder and swam past [the river]." (p. 117)

$\begin{array}{lllllllll}\text { b. ni } & \text { tsunhe } & \text { voi } & \text { tf'oi } & \text { la, } & \text { ni } & \text { na } & \text { 3u } & \text { makkai } \\ \text { You } & \text { just } & \text { can } & \text { blow } & \text { PART } & \text { you } & \text { how } & \text { have } & \text { what } \\ \text { tfen } & \text { punsï. } & & & & & & & \\ \text { true } & \text { talent } & & & & & & & \end{array}$


"The only thing you can do is blow; what kind of true ability do you have?" (p. 128)

\begin{tabular}{|c|c|c|c|c|c|c|}
\hline $\begin{array}{l}\text { yai } \\
\text { I }\end{array}$ & $\begin{array}{l}\text { ts'okpunit } \\
\text { yesterday }\end{array}$ & $\begin{array}{l}\text { hay } \\
\text { walk }\end{array}$ & $\begin{array}{l}\text { liau } \\
\text { PERF }\end{array}$ & $\begin{array}{l}\mathrm{n} \text { fip } \\
\text { fifty }\end{array}$ & $\begin{array}{l}\text { li, } \\
\text { mile }\end{array}$ & $\begin{array}{l}\text { kimpunit } \\
\text { today }\end{array}$ \\
\hline han & samfip & li. & & & & \\
\hline
\end{tabular}

"I walked fifty miles yesterday; today I walked only thirty miles." (p. 131)

d. Kai tfak t'ianlo ma ts'in satman, tatnit

That CL field snail mother utmost hard-working every day

hi fon san noiam ts'eu tfufan.

go go up mountain pick up firewood cook

"The Mother Field Snail is very hard-working; every day [she] goes up the mountains to collect firewood and cook." (p. 136)

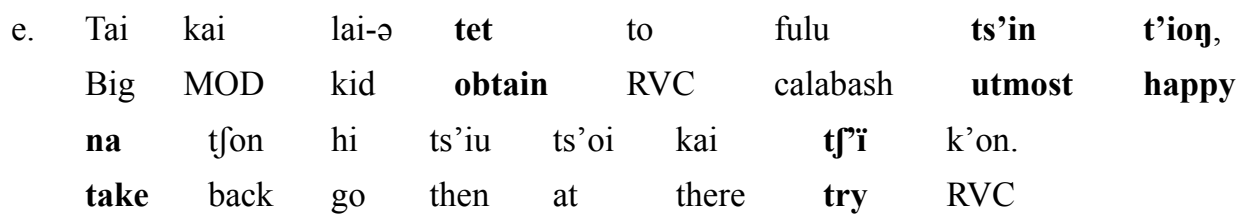

"The oldest kid was so happy to obtain the calabash; (he) took (it) back and tried the function." (p. 153)

The examples in (6a) and (6b) show that the introduction of a subject signals some kind of discourse discontinuity. The repeated occurrence of the same subject also highlights the discontinuity because the presence of a subject forces a repeated subject role to re-enter into the center of play. Examples (6c) and (6d) show that a time signal may break into the continuity of a time span. In (6c), the two temporal expressions signal that each of the individual subevents is proceeding along different timeline. In (6d), the time expression tatnit ("everyday") initiates a new timeline for the second subevent. In (6e), the first subevent expresses the mental state of the kid in his receipt of the gift; the second subevent describes his action with the gift possession. The semantic relationship between the two subevents is unclear; that is, the semantic bond of the two subevents is weak. As shown in (6), even though these sentences contain multiple verbs, they are considered instances of non-SVC due to the violations of (1).

\subsection{Syntactic Tests}

Linguists use different criteria to test the clausehood of a syntactic construction. While Haspelmath (2016) follows the proposal of Bohnemeyer el al. (2007, pp. 500-501) and uses an independent negation as a cross-linguistically applicable test for clausehood, he also cites Cleary-Kemp (2015) and van Staden and Reesink (2008), who argue that it is not possible to find the criteria that can be applied to all languages for measuring the independence of clausehood; instead, they argue that the criteria for clausehood is generally language-specific. The tests used to determine whether a syntactic configuration is mono-clausal or bi-clausal are not universally applicable, but they in general are appropriate to particular languages.

In this paper, we adopt the following criteria to test the independence of clausehood for a serial verb construction, which based on our definition, includes all syntactic configurations that contain multiple verbs, and these verbs share the same subject and indicate subevents that are interdependent to each other. First, we use negation to test monoclausality in the sense that negation has scope over the minimal clause that includes all of these verbs. Second, an SVC is formed on the basis of a complex predicate, which according to Butt (1995), is associated with a functional structure that contains a single subject and a single predicate. Therefore, we use the placement of a subject and the insertion of a conjunction to test monoclausality. Third, it is argued that the component verbs of an SVC should be marked by the same tense, aspect and modality (Aikhenvald, 2006b; Baker, 1989; Brown, 2008; Schiller, 1990), hence we use the placement of an auxiliary to test the scope of a mono-clause. Fourth, we try to switch the order of the verbal complexes to test the interdependence of the two subevents indicated by the verbs. The illustration of syntactic tests is explained in the following Table 1. 
Table 1. Syntactic tests for monoclausality

\begin{tabular}{lll}
\hline Test & Purpose & Result \\
\hline placement of a negation marker $m o$ or $m o i$ & monoclausality & -occur with the first/second verb $\rightarrow$ mono-clause \\
placement of a modal auxiliary & monoclausality & -occur with both of the verbs $\rightarrow$ multi-clause \\
placement of another overt subject & -occur with the first/second verb $\rightarrow$ mono-clause & -occur with both of the verbs $\rightarrow$ multi-clause \\
placement of a conjunction & monoclausality & -occur with one of the verbs $\rightarrow$ mono-clause \\
& monoclausality & -occur with both of the verbs $\rightarrow$ multi-clause \\
the order of verbs & & -yes $\rightarrow$ multi-clause \\
& interdependence of events & -nomo-clause \\
& & -fixed position $\rightarrow$ strong interdependence \\
\end{tabular}

\subsection{Prototypical SVCs}

A prototypical SVC is mono-clausal. It contains at least two verbs in one clause. The two verbs are often contiguous, and their relative order is fixed. The verbs must share the same subject. They are semantically related, and they collaborate to contribute to one event.

\section{Loi/hi-constructions}

Dai (1990) defines syntactic constructions that involve loi and $h i$ as the "verb serialization" type, projecting a sequence of two verbs $\mathrm{V}_{1} \mathrm{~V}_{2}$, and $\mathrm{V}_{1}$ is either the verb loi ("come") or $h i$ ("go"). Some examples are provided in (7), in which $l o i$ and $h i$ directly precede another verb, functioning to introduce a purposive phrase.

$\begin{array}{lllllllll}\text { Pait'ok } & \text { apa } & \text { hi } & \text { ts'ian } & \text { it } & \text { kai } & \text { moinin } & \text { loi } & \text { Jonlion. } \\ \text { Please } & \text { father } & \text { go } & \text { invite } & \text { one } & \text { CL } & \text { matchmaker } & \text { come } & \text { discuss }\end{array}$

"Please, Father, go invite a matchmaker to come to discuss [the matter]" (p. 188)

The syntactic tests are performed in (8).

(8)

Negation

Auxiliary

\section{Overt Subjects}

\section{Conjunction}

\section{Verb Ordering}

$1^{\text {st }}$ verb $\rightarrow$ mo hi ts'iay; mo loi fonlion

$2^{\text {nd }}$ verb $\rightarrow$ *hi mo ts'iany; *loi mo foylion

both verbs $\rightarrow$ *mo hi mo ts'iaj; *mo loi mo foylion

$1^{\text {st }}$ verb $\rightarrow$ oi hi ts'iay; oi loi Joylion

$2^{\text {nd }}$ verb $\rightarrow$ *hi oi ts'ian; *loi oi foylion

both verbs $\rightarrow$ *oi hi oi ts'iay; *oi loi oi Joylion

1 subject $\rightarrow$ gi hi ts'iay; gi loi fonlion

2 subjects $\rightarrow *$ gi hi gi ts'ian; *gi loi gi Jonlion

*hi ienheu ts'ian

*loi tuy Joylion

*ts'ian hi

* Sonlion loi

\section{Serial Resultative Constructions}

When two verbs are juxtaposed, the second one often indicates the result of performing the action of the first verb. The $\mathrm{V}_{1} \mathrm{~V}_{2}$ construction is sometimes identified by Chinese linguists as a compound in which $\mathrm{V}_{2}$ acquires the lexical status as a grammatical particle. However, there are also evidences showing that the $\mathrm{V}_{1} \mathrm{~V}_{2}$ pattern is not always inseparable (Matthews, 2006; Wu, 1992); that is, they can be identified as individual verbs. Some examples of this kind are shown in (9).

$$
\begin{aligned}
& \text { a. zuts'ian nin sionoi na tfon loi....., } \\
& \text { Rich person want to take come back come } \\
& \text { "The rich person wants to take [it] back......" (p. 117) }
\end{aligned}
$$


b. yai tseu lok hoitu se itha fen ne.

I walk fall cape wash in a shortwhile body PART

"I walked into the cape to wash my body for a short while." (p. 187)

c. zoyme-1 pui a tseu.

dragonfly fly PART leave

“The dragonfly flied away." (p.105)

The syntactic tests are performed in (10).

(10)

\begin{tabular}{|c|c|}
\hline \multirow[t]{6}{*}{ Negation } & $1^{\text {st }}$ verb $\rightarrow$ mo na $t$ fon loi; mo tseu lok hoitu; mo pui tseu \\
\hline & $2^{\text {nd }}$ verb $\rightarrow *$ na mo t $\int$ on loi; * tseu mo lok hoitu; *pui mo tseu \\
\hline & both verbs $\rightarrow$ \\
\hline & *mo na mo t $\int$ on loi \\
\hline & *mo tseu mo lok hoitu \\
\hline & *mo pui mo tseu \\
\hline \multirow[t]{3}{*}{ Auxiliary } & $1^{\text {st }}$ verb $\rightarrow$ oi na t $\int$ on loi; oi tseu lok hoitu; oi pui tseu \\
\hline & $2^{\text {nd }}$ verb $\rightarrow$ *na oi t fon loi; *loi oi Joylion; *pui oi tseu \\
\hline & both verbs $\rightarrow$ *oi na oi t $\int$ on loi; *oi loi oi foylion; *oi pui oi tseu \\
\hline \multirow[t]{2}{*}{ Overt Subjects } & 1 subject $\rightarrow$ gi na t $\int$ on loi; gi tseu lok hoitu; gi pui tseu \\
\hline & 2 subjects $\rightarrow$ *gi na gi t $\int$ on loi; *gi tseu gi lok hoitu; *gi pui gi tseu \\
\hline \multirow[t]{3}{*}{ Conjunction } & *na ienheu $\mathrm{t}$ fon loi \\
\hline & *tseu ienheu lok hoitu \\
\hline & *pui ienheu tseu \\
\hline \multirow[t]{3}{*}{ Verb Ordering } & $*$ tfon na loi \\
\hline & *lok tseu hoitu \\
\hline & $*$ tseu pui \\
\hline
\end{tabular}

\section{Shared Object Constructions}

Some linguists regard "shared objecthood" as a significant feature for defining SVCs (Baker, 1989; Stewart, 2001). In Mandarin Chinese, we do find many instances where juxtaposed verbs function like a syntactic compound and that they share not only the same subject but also the same object. Examples are given in (11).

$$
\begin{aligned}
& \text { a. yon-1 tsion p'ak pu na nen oi suy van } \\
& \text { Idiot PAT white cloth take PROG will deliver return } \\
& \text { nin. }
\end{aligned}
$$

Before have one $\mathrm{CL}$ evil monk often do evil

Now, we perform the syntactic tests in the following (12). 
(12)

\section{Negation}

Auxiliary

Overt Subjects

\section{Conjunction}

Verb Ordering $1^{\text {st }}$ verb $\rightarrow$ moi suy van nูin; moi luy p'ian hiogmin

$2^{\text {nd }}$ verb $\rightarrow$ *suy moi van noin; *luy moi p'ian hionmin

both verbs $\rightarrow$ *moi suy moi van nin; *moi lun moi p'ian hionmin

$1^{\text {st }}$ verb $\rightarrow$ oi suy van niin; oi lun p'ian hionmin

$2^{\text {nd }}$ verb $\rightarrow$ *suy oi van nin; *luy oi p'ian hiogmin

both verbs $\rightarrow$ *oi suy oi van ņin; *oi luy oi p'ian hiogmin

1 subject $\rightarrow$ gi suy van ñin; gi luy p'ian hionmin

2 subjects $\rightarrow$ *gi suy gi van ņin; *gi lun gi p'ian hionmin

*suy ienheu van nin

*luy tuy p'ian hionmin

*van suy nin

*p'ian luy hionmin

In this section, we see that the application of the above syntactic tests for all subtypes of prototypical SVCs has shown the same results, which are summarized in Table 2.

Table 2. Syntactic tests for prototypical SVCs

\begin{tabular}{lll}
\hline Test & Purpose & Result \\
\hline placement of a negation marker mo or moi & monoclausality & occur with the first verb $\rightarrow$ mono-clause \\
placement of a modal auxiliary & monoclausality & occur with the first verb $\rightarrow$ mono-clause \\
placement of another overt subject & monoclausality & only 1 subject is allowed $\rightarrow$ mono-clause \\
placement of a conjunction & monoclausality & conjunction is not allowed $\rightarrow$ mono-clause \\
the order of verbs & interdependence of events & fixed position $\rightarrow$ strong interdependence \\
\hline
\end{tabular}

As shown in the table, the negator and the auxiliary only appear before the first verb and they have scope over the sequence of the two verbs. Only one subject is allowed to be present, and the insertion of a conjunction it not allowed. The ordering of verbs is fixed. The two verbs cannot switch their position with one another. These tests show a strong monoclausality for all of the subtypes that are identified into the prototypical SVC category.

\subsection{Non-Prototypical SVCs}

Non-prototypical SVCs also contain multiple verbs, but the constructions are relatively weaker in terms of their monoclausality. The syntactic tests often show contradictory results since syntactic constructions that are classified into the non-prototype do not possess all of the features in (1) and (2). As shown in this section, some tests argue for a mono-clausal analysis while some argue for a bi-clausal analysis regarding the same syntactic construction.

This section identifies seven subtypes of Non-prototypical SVCs. The first three subtypes are argued to be bi-clausal. The syntactic tests give evidence by showing that for these subtypes, each verb can have its own subject; besides, an overt connector is almost always possible. The other four subtypes, contrastively, have stronger monoclausality as most of them allow only one subject, one negative particle, and one modal auxiliary for the verb sequence.

\section{Constructions with an Overt Connector}

Some serial verbs are combined by an overt connector. The connector may indicate different kinds of semantic relationship. For example, in (13), a cause-effect relation, a resultative, and a purposive relation are identified because each sentence contains an overt grammatical indicator that directly points out the semantic relation between the two component verbal constructions.

(13) a

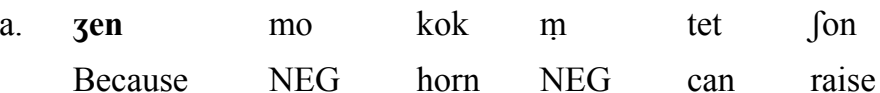

$$
\begin{aligned}
& \text { "Since [the dragon] doesn't have a horn, [he] cannot go up [to the sky]." (p. 115) }
\end{aligned}
$$




$\begin{array}{lllllll}\text { b. Kaiteu } & \text { zatf'u zït } & \text { k'on kian ts'iu hak } & \text { hat } \\ \text { Those } & \text { beast as soon as } & \text { see } & \text { RVC } & \text { turn out } & \text { scare } \\ \text { tet } & \text { p'inmian } & \text { tseu } & \text { la. } & & \\ \text { COMP } & \text { try one's best leave } & \text { PART } & & \end{array}$

"As soon as those beasts saw [them], [they] felt so scared that they tried their best to leave immediately." (p. 125)

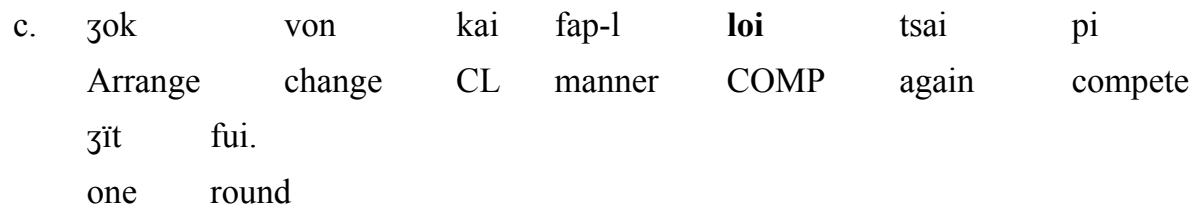

"Let's make an appointment to change the method following which [we will] compete again for another round." (p. 132)

In (22a), the connector zen indicates the cause-effect relation; in (22b), the complementizer tet brings a resultative clause to explain the degree how those beasts have been scared; in (22c), the complementizer loi introduces a purposive phrase to the preceding phrase. The purpose for the attempt to change the method is to run another round of competition.

The following (14) shows that for each kind of syntactic test, there are always syntactic configurations that are compatible with the meaning associated with the syntactic process.

Negation

Auxiliary $1^{\text {st }}$ verb $\rightarrow$

zen mo kok Jon hi......

Kaiteu zat' 'u k'on kian, mo hak tet p'inmian tseu.

moi von kai fap-l loi tsai pi zit fui

$2^{\text {nd }}$ verb $\rightarrow$

zen kok moi fon hi......

Kaiteu zat' 'u k'on kian, hak tet moi p'inmian tseu.

von kai fap-l loi moi tsai pi zït fui

both verbs $\rightarrow$

zen mo kok moi fon......

Kaiteu zat''u k'on kian, mo hak tet moi p'inmian tseu.

moi von kai fap-l loi moi tsai pi zït fui

$1^{\text {st }}$ verb $\rightarrow$

voi zen mo kok ṃ tet $\int o n . . . . .$.

Kaiteu zat' 'u zït k'on kian, ts'iu oi hak tet p'inmian tseu la.

oi von kai fap-l loi tsai pi zït fui

$2^{\text {nd }}$ verb $\rightarrow$

zen mo kok voi ṃ tet fon......

Kaiteu zat' 'u zit k'on kian, ts'iu hak tet oi p'inmian tseu la.

von kai fap-l loi oi tsai pi zit fui

both verbs $\rightarrow$

voi zen mo kok voi ṃ tet $\int o n . . . . .$.

Kaiteu zatf'u zït k'on kian, ts'iu oi hak tet oi p'inmian tseu la.

oi von kai fap-l loi oi tsai pi zït fui 


\author{
Overt Subjects $\quad 1$ subject $\rightarrow$ \\ zen gi mo kok ṃ tet fon...... \\ .......kaiteu zat''u ts'iu hak tet p'inmian tseu la. \\ yaiteu von kai fap-l loi tsai pi zït fui. \\ 2 subjects $\rightarrow$ \\ zen gi mo kok, gi ṃ tet fon...... \\ ......kaiteu zat's'u ts'iu hak tet kaiteu p'inmian tseu la. \\ yaiteu von kai fap-l loi gaiteu tsai pi zït fui.

\section{Conjunction} \\ zen mo kok ṃ tet fon...... \\ Kaiteu zat $\int ' u$ zit k'on kian, ts'iu hak tet p'inmian tseu la. \\ von kai fap-l loi tsai pi zït fui. \\ Verb Ordering \\ $m$ tet Jon zen mo kok. \\ *tet p'inmian tseu la ts'iu hak \\ *loi tsai pi zït fui von kai fap-l.
}

The co-occurring verbs in the examples (13) have potential to be negated at the same time; each has potential to take an individual auxiliary, to include an overt subject in their own structure, to be connected with an overt conjunction, and in some instances they can even switch their position. All these argue for a bi-clausal analysis for this subtype of construction.

\title{
II. Complement Clause
}

There are constructions that involve two verbs, one functions to provide an explanation or context that further explains the other as shown in (15).

$\begin{array}{lllll}\text { (15) a. ninnin } & \text { tu } & \text { ham } & \text { zanvon. } \\ & \text { Everyone } & \text { all } & \text { yell } & \text { do somebody an injustice }\end{array}$

Everyone yelled, "[we were treated] unjustly.” (p. 119)

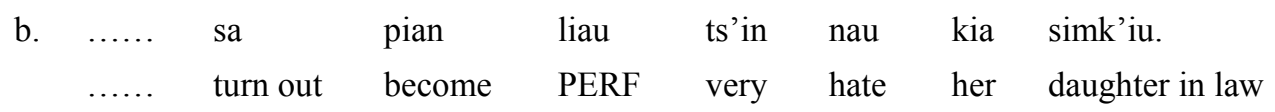

"[She] has become quite disgusted at her daughter in law." (p. 175)

$\begin{array}{lllllllll}\text { c. Kaikuy } & \text { ts'iu } & \text { ti } & \text { pun } & \text { p̣uy } & \text { ts'un } & \text { tsap'ian } & \text { hi } & \text { le } \\ \text { Chicken } & \text { then } & \text { know } & \text { PASS } & \text { centipede } & \text { worm } & \text { deceive } & \text { go } & \text { PART }\end{array}$

"The chicken then knows that [it] has been deceived by the centipede." (p. 116)

In (15a), the verb of saying ham ("yell") requires a clausal complement to further describe the content of speech. In (15b), the clause "be very disgusted at her" functions as the complement of the verb pian ("become"), explaining how the subject has changed her attitude toward her daughter in law. In (15c), the thinking verb $t i$ ("know") also requires a clausal complement "be deceived by the centipede" to further explain the information the chicken knows. In all of the aforementioned cases, the two verbs are connected through the process of complementation.

For this subtype of SVC, the bi-clausal status is as obvious as the previous subtype according to very similar evidence as shown in (16).

Negation

$1^{\text {st }}$ verb $\rightarrow$

n̊inniin tu moi ham ts'in zanvoy.

......sa mo pian liau ts'in nau kia simk'iu.

Kaikun ts'iu ṃ ti pun p̣kun ts'un tsap'ian hi le.

$2^{\text {nd }}$ verb $\rightarrow$

n̋inņin tu ham mo ts'in zanvoy. 


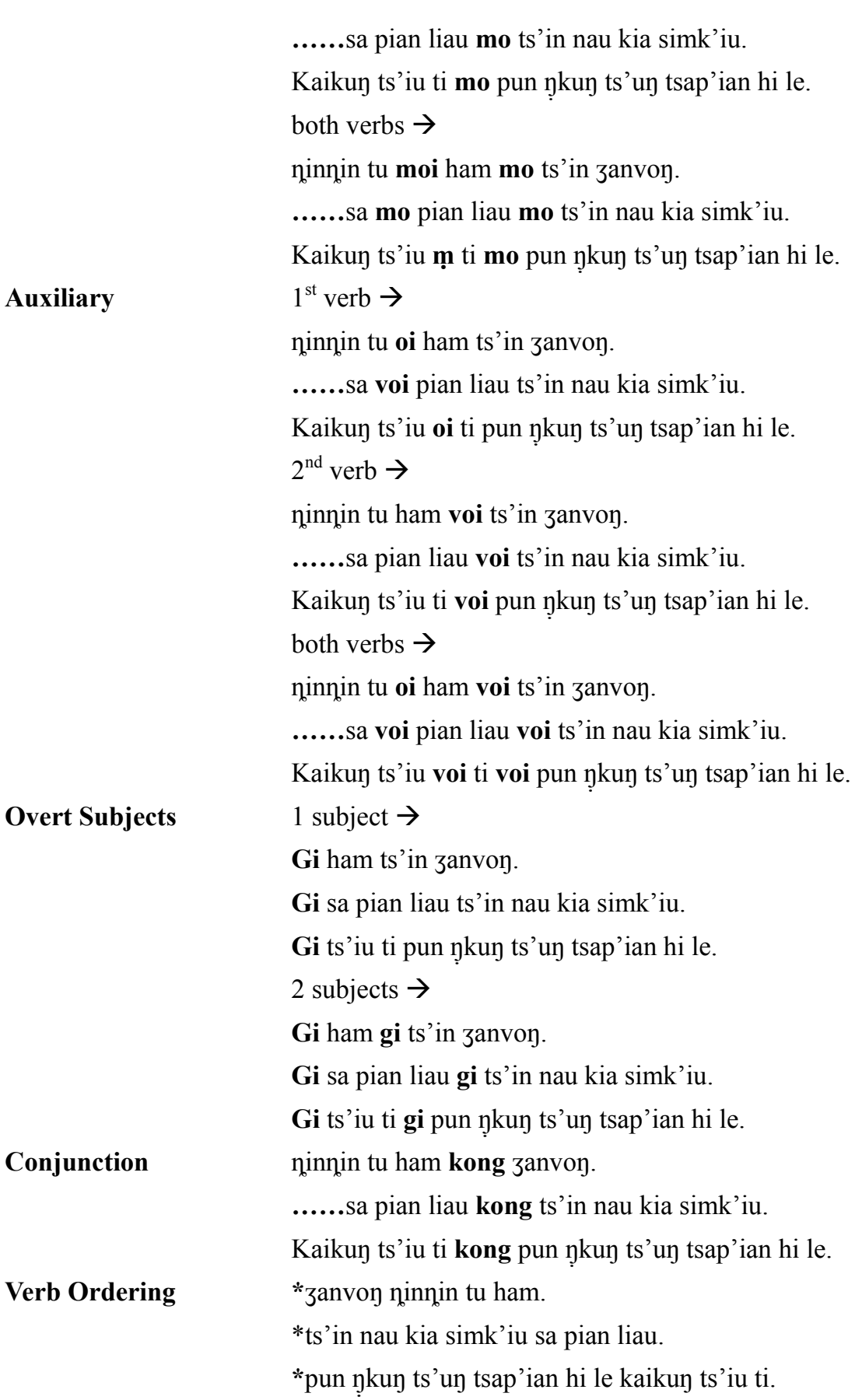

As shown in (16), the two clauses can both be marked by an individual negator, can take separate auxiliaries, can take an individual overt subject, can be intervened by a complementizer kong, arguing for a bi-clausal analysis for the constructions at issue.

\section{Coordination of Events}

In some cases two verb phrases are juxtaposed and parallel to one another, conjoining two subevents through coordination, as shown in (17).
a. T'aika
k'ian $\int \mathrm{u}$
k'ian
kiok loi
t'iauvu ţonko.
dance
sing
Everyone
hold hand
hold
foot to
"Everyone is holding hands and holding feet to dance and sing." (pp. 113-114)

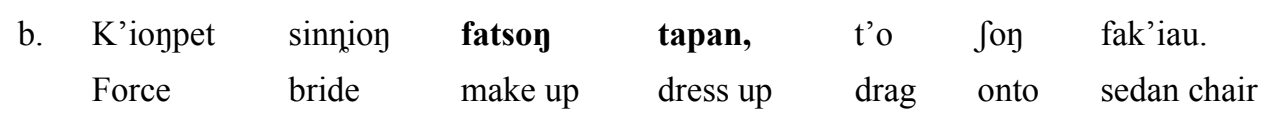


"Force the bride to put makeup on her face and dress up, and then drag her onto the sedan chair." (p. 102)

In (17a), two parallel constructions, hold hands and hold feet, form a unit; another pair of constructions, dance and sing, form another unit. Each unit consists of two coordinated events, and the second unit is set as the purpose for the event indicated by the first unit. They hold their hands and feet in order to dance and sing. All four of the subevents happen simultaneously and cooperate to construct a happy, cheerful wedding scene. In (17b), the two subevents, "put on makeup" and "dress up", indicate the membership on the list that the bride was requested to do. The two subevents are expressed by a series of two verb phrases. The following (18) shows the results of syntactic tests.

Negation

Auxiliary

Overt Subjects

\section{Conjunction}

Verb Ordering

$$
1^{\text {st }} \text { verb } \rightarrow
$$

mo k'ian Ju k'ian kiok; mo t'iauvu t'onko; mo fatsoy tapan

$2^{\text {nd }}$ verb $\rightarrow$

k'ian Ju mo k'ian kiok; t'iauvu mo tf'onko; fatson mo tapan

both verbs $\rightarrow$

mo k'ian fu mo k'ian kiok

mo t'iauvu mo tf'onko

mo fatson mo tapan

$1^{\text {st }}$ verb $\rightarrow$

oi k'ian Ju k'ian kiok; oi t'iauvu tf'opko; oi fatson tapan

$2^{\text {nd }}$ verb $\rightarrow$

*k'ian Ju oi k'ian kiok; *t'iauvu oi tf'oyko; *fatson oi tapan

both verbs $\rightarrow$

oi k'ian Ju oi k'ian kiok

oi t'iauvu oi t'’oyko

oi fatsoy oi tapan

1 subject $\rightarrow$

t'aika k'ian Ju k'ian kiok

t'aika t'iauvu ts'onko

sinnion fatson tapan

2 subjects $\rightarrow$

t'aika k'ian fu t'aika k'ian kiok

t'aika t'iauvu t'aika ts'oyko

sinnion fatsoy sinniog tapan

k'ian Ju tuy k'ian kiok

t'iauvu tun ts'onko

fatson tuy tapan

k'ian kiok k'ian Ju; t f'onko t'iauvu; tapan fatson auxiliary, subject, conjunction, and verb ordering tests.

\section{Manner/Instrument-Act}

Two subevents often cooperate to form a major event. As shown by the two sentences in (19), each of the first verbs indicates the tool or the manner by which the subject carried out the action of the second verb. For this type of construction, the subevents indicated by the two verbs collaboratively contribute to one major event. 


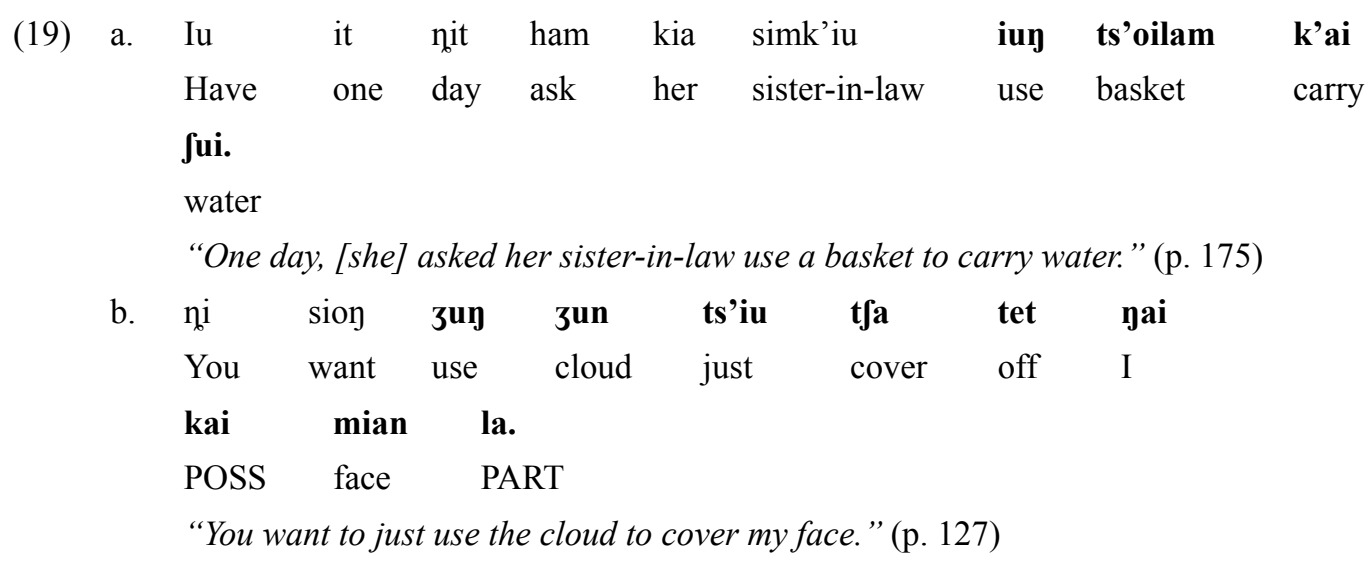

We apply the same syntactic tests to the examples in (20).

\begin{tabular}{|c|c|}
\hline \multirow[t]{7}{*}{ Negation } & $1^{\text {st }}$ verb $\rightarrow$ \\
\hline & moi iun ts'oilam k'ai Jui; moi zuy zun t fa tet yai kai mian \\
\hline & $2^{\text {nd }}$ verb $\rightarrow$ \\
\hline & *iun ts'oilam moi k'ai Jui; *3uy zun moi tfa tet yai kai mian \\
\hline & both verbs $\rightarrow$ \\
\hline & *moi iuy ts'oilam moi k'ai Jui \\
\hline & *moi zuy zun moi tfa tet nai kai mian \\
\hline \multirow[t]{7}{*}{ Auxiliary } & $1^{\text {st }}$ verb $\rightarrow$ \\
\hline & oi iun ts'oilam k'ai Jui; oi zun zun t fa tet yai kai mian \\
\hline & $2^{\text {nd }}$ verb $\rightarrow$ \\
\hline & iuy ts'oilam oi k'ai fui; zuy zun oi t ta tet yai kai mian \\
\hline & both verbs $\rightarrow$ \\
\hline & *oi iuy ts'oilam oi k'ai Jui \\
\hline & *oi zuy zun oi tfa tet yai kai mian \\
\hline \multirow[t]{4}{*}{ Overt Subjects } & 1 subject $\rightarrow$ gi iun ts'oilam k'ai Jui; gi zun zun t $\int a$ tet yai kai mian \\
\hline & 2 subjects $\rightarrow$ \\
\hline & *gi iuy ts'oilam gi k'ai fui \\
\hline & *gi zun zun gi t fa tet yai kai mian \\
\hline \multirow[t]{2}{*}{ Conjunction } & iun ts'oilam hi k'ai Jui \\
\hline & zuy zun loi $t$ fa tet yai kai mian \\
\hline Verb Ordering & k'ai fui iuy ts'oilam; tfa tet yai kai mian zun zun \\
\hline
\end{tabular}

The results imply a mono-clausal analysis by showing that the negative marker moi must appear before the first verb, and the scope must extend over the entire clause. We cannot simply negate the subevent indicated by the second verb. Similarly, the restriction against an overt auxiliary or an overt subject for each of the verbs argues for a strong interdependence between the two subevents. By contrast, the conjunction and the ordering tests suggest a bi-clausal analysis for the same constructions in (19).

\section{Constructions Showing Repetition of Movement}

We also find SVCs consisting of two verbs denoting actions that occur repetitively one after another on the same timeline. Examples are shown in (21).

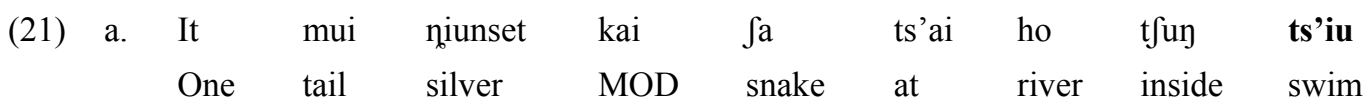


loi ts'iu hi.

come swim go

“A silver snake is swimming swiftly back and forth in the river.” (p. 194)

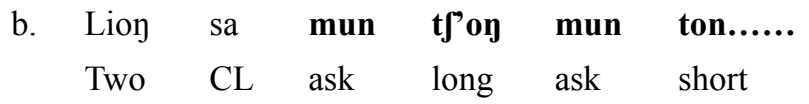

"Two of them asked a lot of questions back and forth......" (p. 172)

In (21a), the actions "swim swiftly here" and "swim swiftly there" are expressed by two consecutive verb phrases. The two phrases are juxtaposed next to one another to show a continuous, repetitive movement. In (21b), the two verb phrases "ask detailed/long questions" and "ask simple/short questions" again indicate two actions that happen repetitively targeting at the same person. The following (22) presents the results of the proposed syntactic tests.

Negation

Auxiliary

\section{Overt Subjects}

\section{Conjunction}

\section{Verb Ordering}

syntactic tests argue for a strong monoclausality for this subtype of SVC. As shown above, only one negator and one auxiliary is allowed, and they must precede the entire VP sequence if they occur. The two verbs must share one overt subject. Verb ordering is usually fixed. The only test that claims a bi-clausal analysis allows the possible insertion of a coordinating conjunction between the two phrases.

\section{Constructions Showing Immediate Result}

Each of the sentences in (23) contains at least two verbs, and the second verb shows the immediate result that takes place as soon as the action indicated by the first verb has been performed.

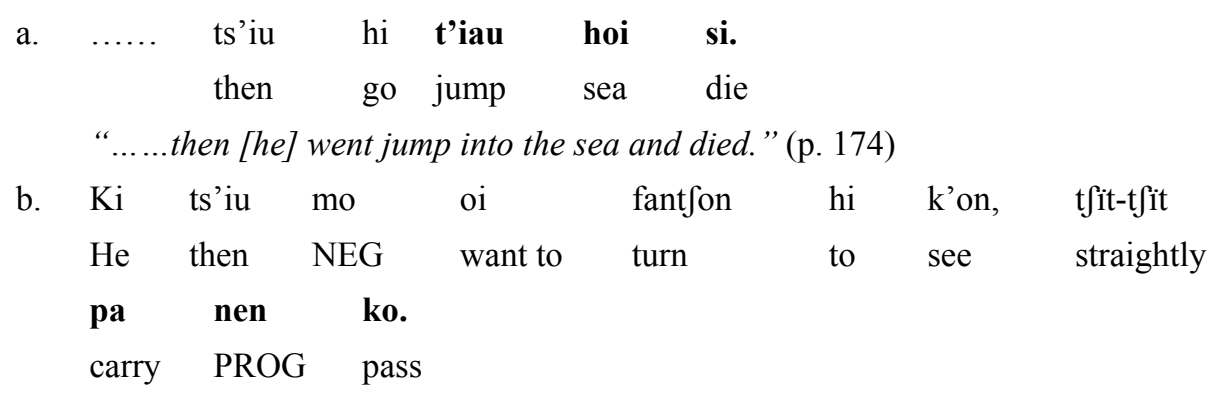

"Then he didn't want to turn his body to see [the ghost]; instead, [he] carried [her] on his shoulder and passed directly." (p. 159)

In (23), the action of the first verb causes an immediate impact as denoted by the second verb. In (23a), the jump instantly causes the death; in (23b), the movement happened right after he carried the ghost onto his shoulder. The syntactic tests are shown in (24).

Negation

$$
\begin{aligned}
& 1^{\text {st }} \text { verb } \rightarrow \text { mo t'iau hoi si; mo pa nen ko } \\
& 2^{\text {nd }} \text { verb } \rightarrow \text { t'iau hoi mo si; pa nen mo ko }
\end{aligned}
$$


both verbs $\rightarrow$ ??mo t'iau hoi mo si; ??mo pa nen mo ko

Auxiliary

Overt Subjects

\section{Conjunction}

Verb Ordering $1^{\text {st }}$ verb $\rightarrow$ oi t'iau hoi si; oi pa nen ko

$2^{\text {nd }}$ verb $\rightarrow$ t'iau hoi oi si; pa nen oi ko

both verbs $\rightarrow$ *oi t'iau hoi oi si; *oi pa nen oi ko

1 subject $\rightarrow$ gi t'iau hoi si; gi pa nen ko

2 subjects $\rightarrow$ *gi t'iau hoi gi si; *gi pa nen gi ko

t'iau hoi ienheu si

pa nen loi ko

*si t'iau hoi; *ko pa nen

According to the results in (24), the negator and the auxiliary are allowed to mark either the first or the second verb, but they do not simultaneously mark both of them. Here we note that if both verbs are negated, the second verb no longer shows the immediate result triggered by the impact of the first verb. Instead, they are bound in a resultative relationship. The interpretation is "he didn't jump into the sea; therefore, he didn't die," in which the first verb does not have a spontaneous, immediate impact on the second verb. The results in (24) also show that the insertion of an overt conjunction is possible, which argues for a bi-clausal analysis. However, the negation, the auxiliary, the subject, and verb ordering tests all speak for a strong interdependence relationship between the two subevents, suggesting a mono-clausal analysis.

\section{Resultative and Purposive Constructions}

We can identify two types of cause-effect relations in Hakka SVCs. In the first type, the event indicated by the first verb leads to the event indicated by the second verb, as in (25a). The second type of relationship describes the situation wherein the second verb indicates a purposive event that causes the action or state of the first verb, as in (25b).

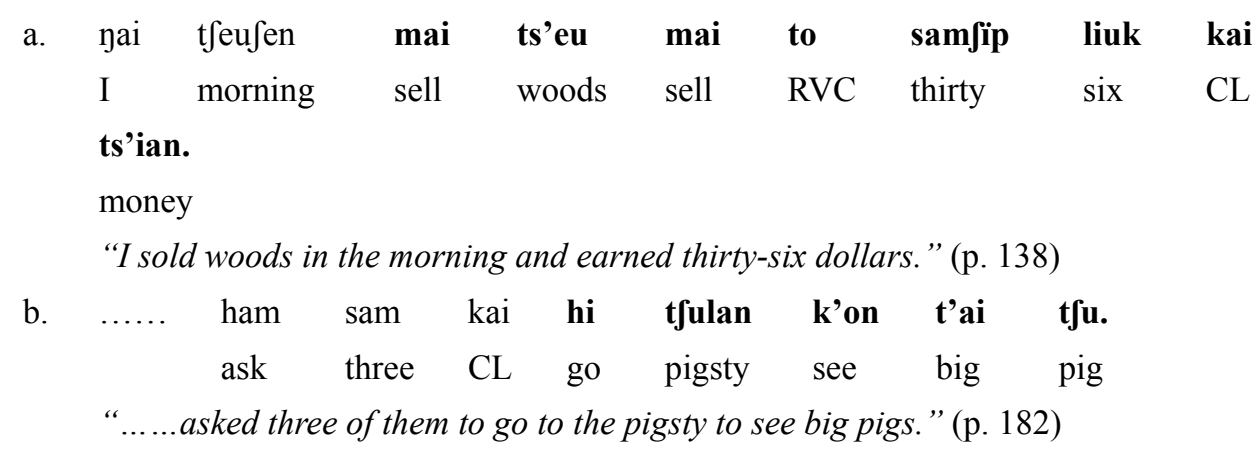

In (25a), the trade results in an income of thirty-six dollars. In (25b), the purpose for the three persons to go to the pigsty is to see the pigs. In both instances, the second verb indicates either the result or the purpose of performing the action of the first verb. The results of syntactic tests are provided in (26).

Negation

$$
\begin{aligned}
& 1^{\text {st }} \text { verb } \rightarrow \text { mo mai ts'eu mai to......; mo hi t fulan k'on t'ai t } \int u \\
& 2^{\text {nd }} \text { verb } \rightarrow \text { mai ts'eu mo mai to......; hi t fulan mo k'on t'ai } t \int u \\
& \text { both verbs } \rightarrow \\
& \text { *mo mai ts'eu mo mai to...... } \\
& \text { mo hi t fulan mo k'on t'ai } t \mathfrak{f u}
\end{aligned}
$$

Auxiliary 


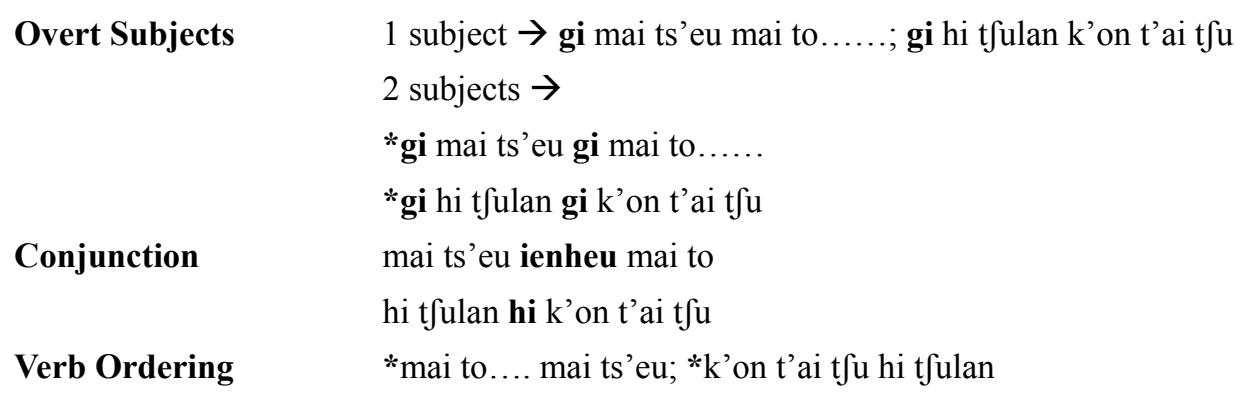

The negator and the auxiliary can occur with either the first or the second verb, and in many cases, they can occur with both verbs at the same time. In addition, the conjunction may appear between the two verbs, suggesting a bi-clausal analysis for the construction. Other syntactic tests, including subject insertion and verb ordering, show a strong interdependence between the two subevents, arguing for a mono-clause analysis.

\section{Discussion-Modify the Prototype Model}

Finally, we summarize the results of syntactic tests for each of the aforementioned subtypes of SVCs as shown in Table 3 below.

Table 3. Syntactic tests to test Hakka SVCs

\begin{tabular}{|c|c|c|c|c|c|}
\hline & NEG & AUX & SUBJ & CONJ & ORDER \\
\hline Loi/hi + V & 1 & 1 & $x$ & $x$ & $x$ \\
\hline Serial Resultative & 1 & 1 & $x$ & $x$ & $x$ \\
\hline Shared Object & 1 & 1 & $x$ & $x$ & $x$ \\
\hline Manner/Instrument & 1 & $1 / 2$ & $x$ & $\checkmark$ & $\checkmark$ \\
\hline Continuation of Movement & 1 & 1 & $x$ & $\checkmark$ & $x$ \\
\hline Immediate Result & $1 / 2$ & $1 / 2$ & $x$ & $\checkmark$ & $x$ \\
\hline Resultative and Purposive & $1+2$ & $1+2$ & $x$ & $\checkmark$ & $x$ \\
\hline Coordination & $1+2$ & $1+2$ & $\checkmark$ & $\checkmark$ & $\checkmark$ \\
\hline Complement Clause & $1+2$ & $1+2$ & $\checkmark$ & $\checkmark$ & $x$ \\
\hline Overt Connector & $1+2$ & $1+2$ & $\checkmark$ & $\checkmark$ & $\checkmark / x$ \\
\hline
\end{tabular}

Based on the results shown in Table 3, we have the following discussions. The discussion of each point will not be attempted in-depth. We will leave them for the matter of future research.

First, concerning the degree of monoclausality, we propose the following hierarchy from the highest to the lowest: Loi/hi Construction, Serial Resultative, Shared Object $>$ Continuation of Movement, Immediate Result $>$ Instrument/Manner-Act $>$ Resultative/Purposive $>$ Coordination, Complement Clause, Overt Clause Connector.

A short summary for each level of the hierarchy is presented here:

\section{Level I: Loi/hi Construction, Serial Resultative, Shared Object}

Negation and auxiliary only occur with the first verb; two overt subjects are not allowed; a conjunction does not appear between the two verbs; the order of the two verbs is fixed.

\section{Level II: Continuation of Movement, Immediate Result}

Negation and auxiliary only occur with either the first or the second verb; two overt subjects are not allowed; a conjunction may appear between the two verbs; the order of the two verbs is fixed.

\section{Level III: Instrument/Manner-Act}

Negation and auxiliary only occur with either the first or the second verb; two overt subjects are not allowed; a conjunction may appear between the two verbs; the order of the two verbs may switch.

\section{Level IV: Resultative/Purposive}

Negation and auxiliary may occur simultaneously with both the first and the second verb; two overt subjects are not allowed; a conjunction may appear between the two verbs; the order of the two verbs is fixed.

\section{Level V: Coordination, Complement Clause, Overt Clause Connector.}

Negation and auxiliary may occur simultaneously with both the first and the second verb; two verbs may have 
their own overt subject; a conjunction may appear between the two verbs; the order of the two verbs is flexible if they are coordinative.

Only the Level I SVCs are prototypical because they fulfill all the conditions that suggest a mono-clausal construction. All the other SVCs are classified into the non-prototypical category. When the two verbs cooperate to form a continuous, repetitive movement, or when one of them indicates an immediate result that takes places because of the impact of the other, they tend to receive a mono-clausal analysis. The strength of monoclausality decreases when one of the verbs indicates the tool or the manner adopted to perform the action of the other verb. The strength of monoclausality decreases even more if the two verbs project two phrases that are bound in a resultative or a purposive relationship. Finally, the monoclausality is the weakest when the two verb appear in two parallel phrasal constructions that are coordinated to indicate the membership on a list, when one of the verb phrases appears to be the complement of another verb, or when two verb phrases are conjoined by an overt clause connector.

The semantic relationship of the two verbs and their monoclausality is shown in Figure 3. According to the diagram, the Level I SVC involves two verbs cooperating in expressing an event. The Level II \& III SVC involves two verbs that have their own semantic field, and they are related to one another with an immediate interrelation defined by cause-result, purpose-goal, or instrument/manner-task relationship. The Level IV \& V SVC involves two verbs that form two subevents, and the two subevents are connected by semantic relevance. As shown here, the greater distance in semantic interdependence between the two verbs forms a gradation deviating from the prototype.
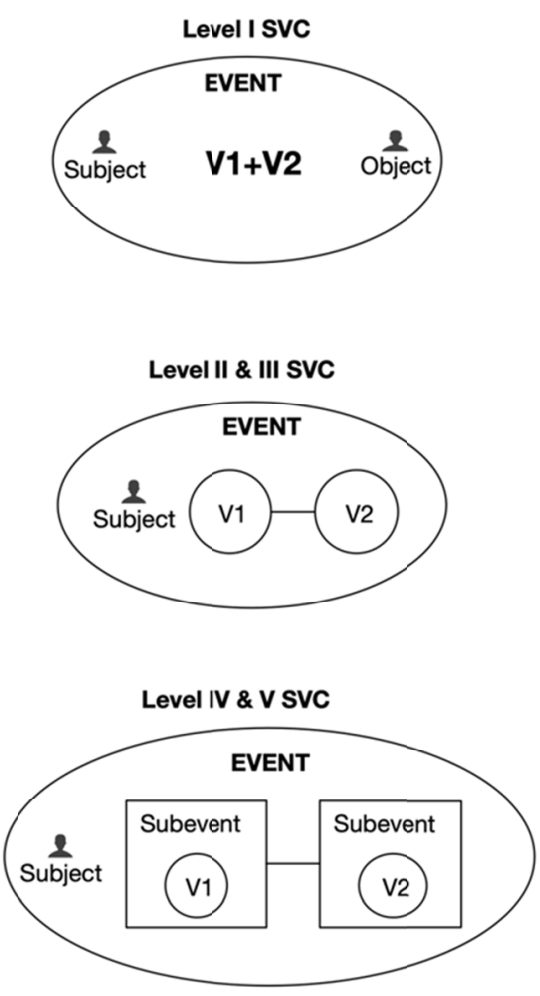

Figure 3. Semantic diagrams of different types of SVC

Second, SVCs that include two coordinated phrases, that include a main verb taking another verb phrase as the complement, and that include an overt connector functioning to combine two verb phrases are considered bi-clausal. These constructions not only allow an overt subject in their own phrase structure, they also show weak semantic and structural interdependence as indicated by the results of other syntactic tests.

Third, the possibility for the negative particle and the auxiliary to occur with either the first or the second verb is related to the issue concerning which verb is the main verb in the clause. If the verb indicating the resultant state, the purpose, or the main act is the second verb in terms of word order, the grammatical indications are allowed to 
mark on either the first or the second verb for the SVCs.

Fourth, in most cases the SVCs allow the presence of only one negative marker and one auxiliary except the constructions that receive a bi-clausal analysis. The contrast is shown in (27). The fact that only one negative marker is allowed argues for a stronger monoclausality for the serial construction.

$$
\begin{aligned}
& \text { a. *.....moi iun ts'oilam moi k'ai fui (Instrument-Act) } \\
& \text { b. *......mo ts'iu loi mo ts'iu hi (Repetitive Movement) } \\
& \text { c. *......mo t'iau hoi mo si (Immediate Result) } \\
& \text { d. *......mo mai ts'eu mo mai to samfip liuk kai ts'ian (Resultative) } \\
& \text { e. ......mo k'ian fu mo k'ian kiok.... (Coordination) } \\
& \text { f. .......mo t'iauvu mo ts'onko (Coordination) } \\
& \text { g. ....... zen mo kok moi fon...... (Overt Connector) } \\
& \text { h. ......moi ham mo ts'in zanvoy...... (Complement Clause) }
\end{aligned}
$$

At this point we can modify the prototype model established earlier in Figure 2 by including more details on the basis of the discussions and classification provided in Section 2. The modified version of the prototype model is shown below in Figure 4.

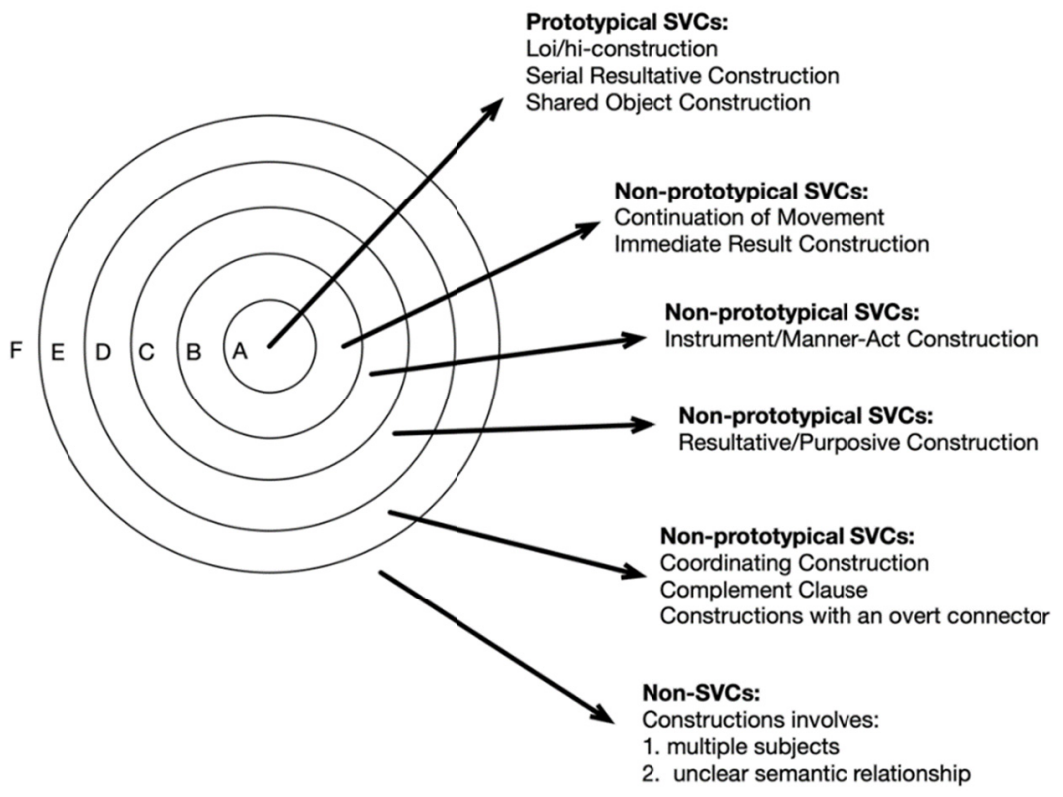

Figure 4. Prototype model of SVCs

The revised SVC model for Hakka is shown in Figure 4. The closer a construction is to the inner circle, the stronger in monoclausality is the construction, and the more prototypical it is as a serial verb construction. Circle A is the innermost circle, including constructions that are identified as the most prototypical type of SVC. The co-occurring verbs in this circle are often juxtaposed, showing high structural and semantic interdependence. Circle B include the subtypes of repetitive movements and immediate impact and result. The constructions are non-prototypical SVCs that are closest to the center and thus have the strongest monoclausality among the other non-prototypical SVCs. Circle C and D are also non-prototypical. In Circle C, two verbs co-occur and shows strong syntactic and semantic interdependence. One verb indicates the manner or instrument adopted to perform the act of another verb. The verbs usually share the same negative scope and happen on the same timeline, as indicated by the restriction that only one negative particle and one auxiliary is allowed in the structure. Circle D contains co-occurring verb phrases that are bound in a resultative or a purposive relationship. The SVC subtype is relatively weaker in monoclausality and the negative and the auxiliary particle are allowed to occur simultaneously with both verbs. Circle E includes those SVCs that are closest to the outermost circle. The co-occurring verb phrases in this circle are connected by coordination, predicate-complement relation, or an 
overt connector. They show the weakest monoclausality and are often argued to be bi-clausal constructions. Finally, the constructions in Circle F are not SVCs. Even though two verbs co-occur in the same sentence, in some cases the semantic relationship between the two verbs is unclear, while in other cases two subjects are present for each verb.

\section{Conclusion}

While disagreement on the definition, properties, and classification of SVC is abundant, this paper seeks to provide a foundation that discusses the construction from different perspectives.

First, Hakka SVC can be investigated with a meaning-based cognitive approach. This paper pursues a categorization of different subtypes of SVCs based on the semantic relationship between the verbs involved. Since the co-occurring verbs in SVC predict two semantically related subevents, we can classify the constructions into different subtypes based on their semantic relationship.

Second, this paper defines SVCs by proposing a prototype model for their construction. In Chinese languages, it is difficult to give a precise definition concerning what kind of linguistic construction can be considered an SVC. This is because Chinese languages, including Hakka, allow the subject to be dropped in many situations, especially in the context where the user is telling a story. Therefore, in this paper we adopt the prototype model to define SVC and try to be as general as possible to include all structural patterns containing two co-occurring verbs in sequential clauses and a shared subject. We also define what should be counted as a prototypical SVC, which is a syntactic configuration that contains two verbs in the same clause; further, the two verbs share the same grammatical subject, and they indicate two highly structurally and semantically interdependent subevents that can be attested by syntactic tests. In addition, this paper also proposes that a greater distance in syntactic and semantic interdependence between the co-occurring verbs forms a gradation deviating from the prototypical SVC.

\section{Acknowledgment}

The research paper is financially supported by the Ministry of Science and Technology in Taiwan under the grant \#MOST-106-2410-H-032-043-.

\section{References}

Aikhenvald, A. Y. (2006a). Serial verb constructions in typological perspective. In A. Y. Aikhenvald \& R. M. W. Dixon (Eds.), Serial Verb Constructions. A Cross-linguistic Typology (pp. 1-68). Oxford: Oxford University Press.

Aikhenvald, A. Y. (2006b). Serial verbs constructions in Tariana. In A. Y. Aikhenvald \& R. M. W. Dixon (Eds.), Serial Verb Constructions. A Cross-linguistic Typology (pp. 178-201). Oxford: Oxford University Press.

Baker, M. C. (1989). Object sharing and projection in serial verb constructions. Linguistic Inquiry, 20(4), 513-553.

Bamgbose, A. (1974). On serial verbs and verbal status. Journal of West African Languages, 9, 17-48.

Bisang, W. (1995). Verb serialization and converbs: differences and similarities. In M. Haspelmath \& E. König (Eds.), Converbs in Cross-linguistic Perspective: Structure and Meaning of Adverbial Forms-Adverbial Partici-ples, Gerunds (pp. 137-188). Berlin \& New York: Mouton de Gruyter.

Bohnemeyer, J., Enfield, N. J., Essegbey, J., Ibarretxe-Antuñano, I., Kita, S., Lüpke, F., \& Ameka, F. K. (2007). Principles of event segmentation in language: The case of motion events. Language, 83(3), 495-532. https://doi.org/10.1353/lan.2007.0116

Bowern, C. (2008). The Diachrony of Complex Predicates. Diachronica, 25(2), 161-185. https://doi.org/10.1075/dia.25.2.03bow

Butt, M. (1995). The Structure of Complex Predicates in Urdu. CA: CSLI Publications.

Chao, Y.-R. (1968). A grammar of spoken Chinese. Berkeley and Los Angeles, CA: University of California Press.

Chen, X. L. (1993). On the Syntax of Serial Verb Constructions in Chinese. Ph.D. dissertation. University of Georgia.

Christaller, J. G. (1875). A Grammar of the Asante and Fante Language called Tshi (Chwee, Twi). Gold Coast: Basel German Evangelical Mission.

Cleary-Kemp, J. (2015). Serial Verb Constructions Revisited: A Case Study from Koro. Berkeley: University of 
California at Berkeley dissertation.

Dai, J. X.-D. (1990). Syntactic constructions in serial verb expressions in Chinese. In Z. A. M. Joseph Brian (Ed.), When Verbs Collide: Papers from the Ohio State Mini-Conference on Serial Verbs (pp. 316-339). Ohio State University.

Fan, Y. (2016). Serial Verb Constructions. In Mandarin Chinese and Jinjiang Southern Min. Ph.D. dissertation. University of Manchester.

Haiman, J. (1983). Iconic and economic motivation. Language, 59, 781-819. https://doi.org/10.2307/413373

Haspelmath, M. (2016). The Serial Verb Construction: Comparative Concept and Cross-linguistic Generalizations. Language and Linguistics, 17(3), 291-319. https://doi.org/10.1177/2397002215626895

Lakoff, G. (1987). Women, Fire, and Dangerous Things: What Categories Reveal about the Mind. Chicago: University of Chicago Press. https://doi.org/10.7208/chicago/9780226471013.001.0001

Langacker, R. W. (1987). Foundations of Cognitive Grammar (Volume 1: Theoretical Prerequisites). Stanford: Stanford University Press.

Li, C. N., \& Thompson, S. A. (1981). Mandarin Chinese: A functional reference grammar. Berkeley, CA: University of California Press.

Matthews, S. (2006). On serial verb constructions in Cantonese. In A. Y. Aikhenvald \& R. M. W. Dixon (Eds.), Serial Verb Constructions. A Cross-linguistic Typology (pp. 69-87). Oxford: Oxford University Press.

Paul, W. (2005). The 'serial verb construction' in Chinese: A tenacious myth and a Gordian knot. The Linguistic Review, 25(3-4), 367-411. https://doi.org/10.1515/TLIR.2008.011

Rosch, E. (1973). On the internal structure of perceptual and semantic categories. In T. E. Moore (Ed.), Cognitive Development and the Acquisition of Language (pp. 111-144). NY: Academic Press. https://doi.org/10.1016/B978-0-12-505850-6.50010-4

Rosch, E. (1975). Cognitive representations of semantic categories. Journal of Experimental Psychology: General, 104, 192-233. https://doi.org/10.1037/0096-3445.104.3.192

Rosch, E. (1977). Human categorization. In N. Warren (Ed.), Studies in Crosscultural Psychology (Volume 1, pp. 1-49). London: Academic Press.

Rosch, E., \& Mervis, C. B. (1975). Family resemblances: Studies in the internal structure of categories. Cognitive Psychology, 7(4), 573-605. https://doi.org/10.1016/0010-0285(75)90024-9

Schiller, E. (1990). On the definition and distribution of serial verb constructions. Working Papers in Linguistics, $39,34-64$.

Steward, J. M. (1963). Some restrictions on objects in Twi. Journal of African Languages, 2(2), 145-149.

Stewart, O. T. (2001). The Serial Verb Construction Parameter. New York: Garland.

Tseng. Y. C. (2017). Iconicity in the syntactic structure of Mandarin Chinese. International Journal of Language Studies, 11(2), 41-66.

van Staden, M., \& Reesink, G. P. (2008). Serial verb constructions in a linguistic area. In G. Senft (Ed.), Serial Verb Constructions in Austronesian and Papuan Languages (pp. 17-54). Canberra: Pacific Linguistics.

Wierzbicka, A. (1985). Oats and wheat: The fallacy of arbitrariness. In J. Haiman (Ed.), Iconicity in Syntax (pp. 311-342). Amsterdam: John Benjamins. https://doi.org/10.1075/tsl.6.16wie

Wu, D. P. (1992). On serial verb constructions. Ph.D. dissertation, University of Maryland, College Park.

Yang, S. F. (1957). The Hakka dialect of Tao-yuan, Taiwan. Taipei: Academia Sinica.

Yin, H. (2012). A Cognitive Approach to Serial Verb Constructions in Mandarin Chinese. Xiamen University Press.

Yip, P. C., \& Rimmington, D. (2016). Chinese: A Comprehensive Grammar. New York, NY: Routledge.

\section{Note}

Note 1. $C L=$ classifier; $C O M P=$ complementizer; $M O D=$ modifier marker; $N E G=$ negative marker; $P A R T=$ particle; $\mathrm{PAT}=$ patient marker; $\mathrm{PERF}=$ perfective; $\mathrm{PROG}=$ progressive; $\mathrm{REL}=$ relative clause marker; $\mathrm{RVC}=$ resultative verbal construction. 


\section{Copyrights}

Copyright for this article is retained by the author, with first publication rights granted to the journal.

This is an open-access article distributed under the terms and conditions of the Creative Commons Attribution license (http://creativecommons.org/licenses/by/4.0/). 